\title{
Relational variables in short-term psychodynamic psychotherapy: an effectiveness study
}

\author{
Annalisa Tanzilli, ${ }^{1}$ Michele Majorana, ${ }^{2}$ Laura Fonzi, ${ }^{2}$ Mauro Pallagrosi, ${ }^{2}$ Angelo Picardi, ${ }^{3}$ \\ Maria Antonietta Coccanari de' Fornari, ${ }^{2}$ Massimo Biondi, ${ }^{2}$ Vittorio Lingiardi ${ }^{1}$
}

${ }^{1}$ Department of Dynamic and Clinical Psychology, Faculty of Medicine and Psychology, Sapienza University of Rome; ${ }^{2}$ Department of Neurology and Psychiatry, Sapienza University of Rome; ${ }^{3}$ Centre of Behavioral Sciences and Mental Health, Italian National Institute of Health, Rome, Italy

\begin{abstract}
This study examined associations between specific elements of therapeutic relationships and short-term psychodynamic psychotherapy (STPP) outcomes. Notably, we focused on therapists' subjective experiences during their first clinical interaction with patients, countertransference patterns and therapeutic alliance evaluated early in treatment, in relation to patient symptom changes at the end of STPP. Twenty clinicians completed the Comprehensive Psychopathological Rating Scale to evaluate patients' $(N=32)$ symptom severity at the beginning and end of STPP. They also completed the Assessment of Clinicians' Subjective Experience (ACSE) to assess their subjective experiences of their patients at the first clinical interview and the Therapist Response Questionnaire (TRQ) and Working Alliance Inventory to evaluate their countertransference reactions and therapeutic alliance at the sixth therapy session. The findings showed that the TRQ and ACSE scales correlated in a coherent way, with the exception of the TRQ helpless/inadequate pattern and ACSE impotence. Strong and more negative TRQ countertransference patterns and ACSE dimensions were significantly associated with lower quality of the therapeutic alliance. Finally, better STPP outcomes were positively associated with a good therapeutic alliance and negatively correlated with greater difficulty in attunement at the beginning of clinical assessment and therapists' stronger responses of helplessness, frustration, and disengagement during therapy. These results confirm the precious value of the clinical relationship, which represents a useful source of information for therapists when planning therapeutic interventions.

Acknowledgments: the authors would like to thank all the clini-
\end{abstract} cians who contributed to this research: D. Biondi, G. M. Carluccio, A. Corrado, A. De Felice, E. De Sanctis, F. Della Rocca, C. D’Onofrio, E. Fabi, M. Fojanesi, E. Galasso, M. Gallo, S. Inguscio, F. Macrì, F. Missi, V. Monaco, A. Riccardi, L. Todini, L. Vergnani, L. Vescera, R. Zani.

Citation: Tanzilli, A., Majorana, M., Fonzi, L., Pallagrosi, M., Picardi, A., Coccanari de' Fornari, M. A., ... Lingiardi, V. (2018). Relational variables in short-term psychodynamic psychotherapy: an effectiveness study. Research in Psychotherapy: Psychopathology, Process and Outcome, 21(3), 190-200. doi: 10.4081/ripppo.2018.327

Contributions: the authors contributed equally.

Conflict of interest: the authors declare no potential conflict of interest.

Funding: none.

Received for publication: 30 July 2018.

Revision received: 15 August 2018.

Accepted for publication: 16 August 2018.

This work is licensed under a Creative Commons Attribution NonCommercial 4.0 License (CC BY-NC 4.0).

CCopyright A. Tanzilli et al., 2018

Licensee PAGEPress, Italy

Research in Psychotherapy:

Psychopathology, Process and Outcome 2018; 21:190-200

doi:10.4081/ripppo.2018.327

Key words: Short-term psychodynamic psychotherapy; Therapeutic alliance; Outcome; Countertransference; Subjective experience.

\section{Introduction}

Short-term psychodynamic psychotherapy (STPP) is a treatment form that was conceptually and technically derived from long-term psychoanalytic and psychodynamic therapy models. Its goals are to explore and work with the unconscious motives, feelings, and processes that underpin or perpetuate a wide range of mental disorders, symptoms, and clinical conditions that are frequently seen in mental health services and private settings (e.g., Abbass et al., 2014; Gabbard, 2009). With regard to its formal characteristics, it is both time limited (typically ranging 16-30 sessions) and performed in a face-to-face setting, usually with one session per week. Other distinctive elements include: identifying and adhering to a therapeutic goal while attending to termination issues; fostering a good therapeutic alliance; maintaining a high degree of therapist activity; and actively focusing on the here-andnow dimension of the therapeutic relationship (e.g., Leichsenring, Rabung, \& Leibing, 2004). In a review, 
Blagys and Hilsenroth (2000) analyzed the process and techniques of manualized psychodynamic therapy, and identified seven key features of STPP, including: i) a focus on affect and emotional expression of emotion; ii) exploration of attempts to avoid distressing thoughts and feelings; iii) identification of recurring themes and patterns; iv) discussion of past experience; v) a focus on interpersonal relations; vi) a focus on the therapeutic relationship; and vii) exploration of the fantasy life (for a deeper discussion of the principles that inform these strategies, see, e.g., Gabbard, 2009; McWilliams, 2004).

Although systematic process-outcome research on STPP has been more limited than empirical investigations of other treatment brands, several studies have demonstrated the efficacy and effectiveness of STPP in treating a spectrum of disorders, psychiatric symptoms, and interpersonal problems (e.g., Abbass et al., 2014; Driessen et al., 2015; Fonagy, 2015; Keefe, McCarthy, Dinger, Zilcha-Mano, \& Barber, 2014; Leichsenring et al., 2004, 2015). However, the mechanisms of the therapeutic action that accounts for this efficacy/effectiveness are difficult to determine, and more studies are needed to identify the active change agents of STPP and to answer the crucial question of "what works in psychotherapy" (e.g., Castonguay \& Beutler, 2006; Lambert, 2013; Levy, Ablon, \& Kächele, 2012; Wampold \& Imel, 2015).

Over the years, the clinician-patient relationship has consistently proven to be a critical outcome factor in a broad array of treatments (Norcross \& Lambert, 2018; Wampold, 2015; see also Campbell, Norcross, Vasquez, \& Kaslow, 2013). Notably, among the relational (i.e., common or non-specific) therapeutic factors, the alliance - usually defined as the emotional bond that is established in the therapeutic dyad and the agreement between the patient and the therapist concerning the goals of the therapy and the tasks necessary to achieve them (Bordin, 1979) has been shown to be one of the most powerful predictors of psychotherapy success (e.g., Horvath \& Bedi, 2002; Horvath, Del Re, Flückiger, \& Symonds, 2011; Martin, Ganske, \& Davis, 2000). A recent meta-analysis by Flückiger, Del Re, Wampold, and Horvath (2018) of approximately 300 independent studies on alliance-outcome relations indicated that the overall weighted average effect size was $r=.278$ (95\% CIs [.256, .299], $\mathrm{P}<.001)$, corresponding to about $8 \%$ of the variability in therapy outcomes. Moreover, the positive effect of the alliance on promoting meaningful therapeutic change was found to be consistent and robust, regardless of the patient's (intake) clinical condition and related symptoms, the treatment approach, the perspective of the assessor, the alliance and outcome measures used, and the time of evaluation (Flückiger, Del Re, Wampold, \& Horvath, 2018).

While some studies have focused on the specific role of the therapeutic alliance in STPP, the findings provide only weak support for the direct effect of the alliance in predicting STPP outcomes. Clinical observations and re- search suggest that the outcome of STPP may be more influenced by the interaction between the therapeutic alliance, other relational and/or technical factors, as well as therapists' characteristics; however, the complex processes underlying these associations are not clear (e.g., Crits-Christoph \& Connolly, 1999; Gaston, Thompson, Gallagher, Cournoyer, \& Gagnon, 1998; Hersoug, 2004; Hilsenroth, Cromer, \& Ackerman, 2012; Knekt et al., 2012; Lingiardi, Muzi, Tanzilli, \& Carone, 2018; Tanzilli, Colli, Gualco, \& Lingiardi, 2018).

Another relevant component of the therapeutic relationship that has been shown to benefit treatment irrespective of the theoretical-clinical approach is countertransference (or, in this context, the therapist's emotional response/reaction) (e.g., Gelso, 2014; Hayes, Gelso, \& Hummel, 2011). Only a small number of studies has sought to connect countertransference with psychotherapy outcomes, presumably due to the lack of a clear and shared conceptual definition of countertransference (which includes both conscious and unconscious aspects) and the difficulty of operationalizing and measuring it in a clinically sensitive and psychometrically robust manner (e.g., Gelso \& Hayes, 2007). However, in recent years, empirical efforts in this area have increased. A recent meta-analysis of countertransference research using different theoretical definitions and assessment methods (Hayes, Gelso, Goldberg, \& Kivlighan, 2018) showed that (both distal and proximal) treatment outcomes were significantly but poorly associated with countertransference $(r=-16, \mathrm{P}=.02,95 \% \mathrm{CI}[-.30,-.03], d=-0.33, k=14$ studies, $N=973$ ); conversely, outcomes were largely related to countertransference management $(r=.39, \mathrm{P}<.001,95 \% \mathrm{CI}$ $[.17, .60], d=0.84, k=9$ studies, $N=392$ participants). Moreover, some studies showed an inverse relation between specific countertransference behaviors (such as avoidance and detachment) and a greater alliance (Hayes et al., 2011). These research findings suggest that therapists should monitor their subjective reactions and manage them to maintain a sufficiently strong therapeutic relationship and to provide the most effective intervention to their patients. This position is at least as apt for brief therapy as it is for longer treatment, although it is important to highlight that, in SPTT: i) therapists do not have much time to recover from therapeutic mistakes tied to their negative countertransference reactions, and ii) the sense of urgency created by the need for brevity and patient change over a short period of time may create unique countertransference patterns that require therapists' attention and management (Gelso, 2004).

Overall, future process-outcome studies on STPP should examine elements of the therapeutic relationship in greater depth. The research and meta-analyses cited above point to potential negative effects (when left unchecked) and benefits (when properly recognized and managed) of countertransference in relation to psychotherapy outcomes, as well as the importance of devel- 
oping and maintaining a positive alliance for enhancing treatment efficacy/effectiveness; however, to our knowledge, a few empirical investigations have jointly looked at these clinical phenomena in STPP.

The present study sought to address this gap in the empirical literature on STPP by investigating - in a naturalistic sample of psychiatric patients - the relationships between countertransference patterns and the early therapeutic alliance, and patients' changes in symptoms at the end of STPP. Moreover, it pays particular attention to therapists' subjective experiences of patients during their first clinical interaction in relation to STPP outcome.

Notably, countertransference was assessed with the empirically supported version of the Therapist Response Questionnaire (TRQ) (Betan, Heim, Zittel Conklin, \& Westen, 2005; Tanzilli, Colli, Del Corno, \& Lingiardi, 2016). The TRQ is a 79-item clinician-report questionnaire that measures a wide spectrum of thoughts, feelings, and behaviors expressed by therapists toward their patients in psychotherapy, and includes nine patterns of therapists' emotional responses that are conceptually coherent, clinically sensitive, and psychometrically robust: helpless/inadequate, overwhelmed/disorganized, positive/satisfying, hostile/angry, criticized/devalued, parental/protective, special/overinvolved, sexualized, and disengaged. Moreover, therapists' subjective experiences to patients were evaluated with the Assessment of Clinician's Subjective Experience questionnaire (ACSE) (Pallagrosi et al., 2014). The ACSE is a 46-item clinician-report measure consisting of five scales: tension, difficulty in attunement, engagement, disconfirmation, and impotence. All scales have been shown to have excellent validity and reliability.

It is important to highlight that this was the first study to have employed these two instruments in a process-outcome research design; thus, the study also enabled us to examine the clinical applicability of these measures in studies of STPP. Noteworthy, the TRQ is usually used in empirical investigations of the impact of patient pathology on clinicians' reactions in psychotherapy. Research using the TRQ has suggested that specific types of patients particularly those with personality disorders/traits - evoke distinct therapist reaction patterns that are difficult to manage in treatment and which may promote unfavorable outcomes (e.g., Betan et al., 2005; Colli, Tanzilli, Dimaggio, \& Lingiardi, 2014; Lingiardi, Tanzilli, \& Colli, 2015; Tanzilli, Lingiardi, \& Hilsenroth, 2018; Tanzilli, Muzi, Ronningstam, \& Lingiardi, 2017). Conversely, the ACSE has mostly been used in psychiatric contexts, and, consistent with a phenomenological approach, studies using this measure have demonstrated that patients' psychiatric diagnoses or psychopathological dimensions are strongly related to particular subjective experiences in mental health professionals during their first clinical assessment of the patient (e.g., Pallagrosi, Fonzi, Picardi, \& Biondi, 2016; Picardi, Pallagrosi, Fonzi, \& Biondi, 2017). The use of these measures in the present study enabled us to explore the relationships that might exist among TRQ patterns and ACSE dimensions and to investigate the link between these different but related constructs. More specifically, the research focused on three main goals, with the following hypotheses:

Hypothesis 1: Using exploratory analysis, examine whether specific TRQ scales are significantly related to distinct ACSE dimensions in a conceptually coherent way. On the basis of the literature (e.g., Pallagrosi et al., 2014, 2016; Tanzilli et al., 2016), we hypothesized that TRQ positive/satisfying, parental/protective, and special/overinvolved countertransference patterns would be positively associated with ACSE engagement; both TRQ hostile/angry and criticized/devaluated countertransference patterns would be positively associated with both ACSE tension and disconfirmation; the TRQ disengaged countertransference pattern would be positively associated with ACSE difficulty to attunement and negatively related to ACSE engagement; the TRQ helpless/inadequate countertransference pattern would be positively related to ACSE impotence; and the TRQ sexualized countertransference pattern would be positively related to ACSE tension.

Hypothesis 2: Study the relationships among ACSE dimensions, TRQ countertransference patterns, and the quality of the therapeutic alliance evaluated early in treatment. In line with previous research and the meta-analysis described earlier in this section, we hypothesized that weaker alliance would be associated with therapists' more negative and intense countertransference patterns (such as helpless/inadequate, criticized/devalued, and overwhelmed/disorganized) and subjective experiences of their first clinical evaluation of a patient (in particular, impotence, difficulty in attunement, and disconfirmation).

Hypothesis 3: Examine the STPP outcome hypothesizing that patients' symptom severity at the end of treatment would be significantly lower than their initial symptom severity (at the start of therapy). Moreover, according to the clinical and empirical literature on both short- and long-term psychodynamic treatment (e.g., Dahl, Røssberg, Bøgwald, Gabbard, \& Høglend, 2012; Levy et al., 2012; see also this section), we sought to examine whether a higher degree of symptom improvement in patients would be positively associated with higher levels of clinician engagement in the first interactions, as well as more positive countertransference patterns and a higher quality of therapeutic alliance, as assessed early in psychotherapy.

\section{Materials and Methods}

\section{Setting and sampling}

This study was conducted in two psychiatric outpatient centers of the Italian National Health System in Rome, where patients are admitted to STPP after thorough 
diagnostic screening by a team of expert psychiatrists and psychologists. All patients are assigned to members of the dynamic psychotherapy treatment team ecologically and on the basis of clinician availability and caseload. Drawing on the rosters of these centers, we included a group of patients in the study according to the following inclusion and exclusion criteria: i) aged 18 years or older; ii) no psychotic disorder or syndrome with psychotic symptoms; and iii) no mental retardation or clinically relevant cognitive impairment. The treating clinicians were asked to complete a battery of assessment instruments at the beginning and end of treatment. Twelve clinicians provided data on a single patient, whereas the others evaluated more than one patient in their care. All clinicians participated in this research on a volunteer basis, with no remuneration. It was explained to the clinicians that the research investigates the process-outcome of psychodynamic psychotherapy; following this, written informed consent was obtained. The study protocol received ethics approval from the local research ethics review board.

\section{Therapists}

The sample consisted of 20 Caucasian clinicians, including 11 women and 9 men. There were 12 junior and 8 senior psychiatrists with a main age of 34.9 years (standard deviation, $S D=3.56$; range $30-44$ ). Their average length of clinical experience as psychotherapists was 4 years $(S D=3.79$, range $=2-18)$, and they each performed at least 10 hours of direct patient care per week. Their main clinical-theoretical approach was psychodynamic $(N=17)$; other theoretical orientations were metacognitive-interpersonal $(N=2)$ and humanistic $(N=1)$.

\section{Patients}

The sample consisted of 32 Caucasian patients, of whom 16 were women. The mean age was 44 years $(S D=15.31)$. Table 1 shows the demographic information of the patient group, as well as the Axis I and Axis II diagnoses, in accordance with the DSM-IV-TR (APA, 2000). Overall, the sample consisted of mood- or anxiety-disordered patients with relational problems, as demonstrated by the Axis II personality disorders and subclinical traits/features.

\section{Treatment}

All of the patients in the study received a psychological evaluation in order to identify and understand their current problems in living, as well as to assess the appropriateness of STPP. Individual treatments consisting of weekly sessions over 6 months were informed by specific technical guidelines (Blagys \& Hilsenroth, 2000). Overall, clinicians used mostly clarification to increase patients' awareness of their communication and to facilitate the discussion of suppressed material, but also provided supportive interventions to enhance the alliance. Moreover, they encouraged patients to access their emotional experiences and verbalize painful affects connected to difficult events and issues in their life; and addressed repetitive, often maladaptive, behavioral patterns, especially in the interpersonal domain (see Gabbard, 2009). Clinicians received weekly supervision on their clinical interventions by an expert psychodynamic psychotherapist for a minimum of 2 hours each week.

\section{Measures}

Comprehensive Psychopathological Rating Scale

The Comprehensive Psychopathological Rating Scale (CPRS) (Äsberg, Perris, Schalling, \& Sedvall, 1978) measures the severity of psychiatric pathology. It consists of 66 items covering a wide range of psychiatric symptoms/signs: 40 symptoms based on the patient's subjective report, 25 signs based on observations made during the clinical interview, and a global rating indicating the severity of mental illness. CPRS items relate to depressive and suicidal thoughts; psychotic phenomena; reduced sleep, appetite and sexual interest; loss of concentration; anxiety, worry and phobia; fatigue and lassitude; and muscle aches and pains. The presence of clearly defined symptoms or signs of mental disorder was rated on a 4-point Likert scale ranging from 0 to 3 ( $0=$ not present; $1=$ doubtful whether present, and not interfering with life; $2=$ definitely present and of moderate severity; $3=$ severe or incapacitating). Global estimates of the severity of patients' psychiatric pathology were obtained by summing the scores

Table 1. Patients' characteristics $(N=32)$.

\begin{tabular}{lc}
\hline Patients' variables & $N$ \\
\hline Sex & 32 \\
\hline Male & 16 \\
\hline Female & 16 \\
\hline Mean age (SD) & $44(15.31)$ \\
\hline DSM-IV-TR Axis I diagnosis & 13 \\
\hline Depressive disorder & 4 \\
\hline Dysthymic disorder & 3 \\
\hline Bipolar disorder & 10 \\
\hline Anxiety disorder & 1 \\
\hline Adjustment disorder & 1 \\
\hline Impulse control disorder & 3 \\
\hline DSM-IV-TR Axis II diagnosis & 9 \\
\hline Axis II cluster A & 3 \\
\hline Axis II cluster B & 2 \\
\hline Axis II cluster C & \\
\hline Axis II traits/features & \\
\hline$S D$, standard deviation; DSM-IV-TR, Diagnostic and statistical manual of mental disorders \\
(APA, 2000).
\end{tabular}


of each CPRS item. Notably, the CPRS has been properly used for evaluating treatment outcomes that are conceptualized and operationalized in terms of symptom change (Äsberg \& Schalling, 1979).

\section{Assessment of clinicians' subjective experience}

The ACSE (Pallagrosi et al., 2014) is a clinician-report instrument that measures clinicians' subjective experiences during their first interaction with a patient. It consists of 46 items, each rated on a 5-point Likert scale ranging from 0 (not at all) to 4 (very much). The instrument consists of five scales that were factorially derived: i) tension, ii) difficulty in attunement, iii) engagement, iv) disconfirmation, and v) impotence. The tension scale consists of items indicating physical tension and awkwardness, as well as feelings of worry, anxiety, and vigilance. The difficulty in attunement scale contains items describing difficulties in establishing emotional contact, being empathic, understanding the patient's experience, and communicating with the patient. The engagement scale includes items describing the clinician's degree of involvement with the patient. More specifically, feelings of boredom, detachment, and lack of attention indicate low levels of engagement, whereas desire to take care of the patient, feelings of involvement in the clinician-patient relationship, emotional closeness, and tenderness indicate high levels of engagement. The disconfirmation scale consists of items describing a failure to establish an authentic relationship with the patient and feelings of being rejected, criticized, or devalued by the patient. The impotence scale contains items indicating feelings of helplessness, desolation, emptiness, loneliness, and being drained. In the present study, the internal consistency of the ACSE scales, as measured by Cronbach's alpha, was excellent (Streiner, 2003): tension, .90; difficulty in attunement, .87; engagement, .88; disconfirmation, .75; and impotence, .76 .

\section{Therapist Response Questionnaire}

The TRQ (Betan et al., 2005) is a clinician report instrument that assesses therapists' emotional responses to a patient in clinical practice. It consists of 79 items that measure a wide spectrum of thoughts, feelings, and behaviors expressed by therapists toward the patient. Clinicians evaluate each item on a 5-point Likert scale, ranging from 1 (not true) to 5 (very true). In the present study, we used the empirically supported TRQ version (Tanzilli et al., 2016) that included nine countertransference patterns: i) helpless/inadequate, which indicates feelings of inadequacy and incompetence, as well as a strong sense of inefficacy; ii) overwhelmed/disorganized, which describes an intense feeling of being overwhelmed by the patient's emotions and needs, as well as confusion, anxiety, or repulsion; iii) positive/satisfying, which describes an experience of close connection, trust, and collaboration with the patient; iv) hostile/angry, which describes feelings of anger, hostility, and irritation toward the patient; v) criticized/devalued, which describes a sense of being criticized, dismissed, or devalued by the patient; vi) parental/protective, which captures a wish to protect and nurture the patient in a parental way; vii) special/overinvolved, which indicates that the patient is very special, so much so that the clinician may show some difficulty in maintaining the boundaries of the therapeutic setting; viii) sexualized, which describes the presence of sexual tension or attraction toward the patient; and ix) disengaged, which describes feelings of annoyance, boredom, withdrawal, or distraction in sessions. In this study, the nine TRQ factors showed excellent internal consistency (Streiner, 2003), as measured by Cronbach's alpha: criticized/devalued, .87; helpless/inadequate, .93; positive/satisfying, .88; parental/protective, .78; overwhelmed/ disorganized, .81; special/overinvolved, .76; sexualized, .77; disengaged, .88 ; and hostile/angry, .86 .

\section{Working Alliance Inventory - Therapist Version}

The Working Alliance Inventory-Therapist version (WAI-T) (Horvath, 1981; Horvath \& Greenberg, 1986, 1989) assesses the degree of the therapeutic alliance from the clinician's perspective. It is based on Bordin's (1979) pantheoretical model and consists of 36 items rated on a 7-point Likert scale, ranging from 1 (never) to 7 (always). The WAI consists of the following three scales: i) the goal subscale, which refers to agreement regarding the goals of therapy; ii) the task subscale, which concerns agreement regarding the tasks that are necessary to achieve treatment goals; and iii) the bond subscale, which refers to the mutual relationship between the patient and the therapist. In this study, the total score of the WAI-T was used. Research has found robust support for the reliability of the WAI and strong relationships between the therapeutic alliance and a variety of outcome indices (e.g., Horvath \& Bedi, 2002; Horvath \& Greenberg, 1989).

\section{Procedure}

After clinicians provided written agreement to participate in the study, they were asked to evaluate the severity of their patients' psychiatric pathology using the CPRS, as well as their subjective experiences of their patients at the first interaction with them, using the ACSE. At the sixth therapy session, they completed the TRQ to assess their emotional responses to their patients. We used this interval between the ACSE and TRQ because the measures require different administration times: the ACSE must be filled in after the first evaluation, whereas the TRQ must be administered after a minimum of six sessions (but is more typically administered after eight), in order to maximize the likelihood that clinicians will know the patients well enough to describe them with reasonable accuracy. At the sixth session, clinicians also completed the WAI-T to provide their views of the early therapeutic alliance. The focus of the study was on the early psy- 
chotherapy process - drawn from post-session ratings of the first 6 of 30 session treatment protocols - because: i) dropouts generally occur within the first few phases of treatment; and ii) among the potential predictors of premature psychotherapy termination, relationship factors have been shown to have an important influence (e.g., Roos \& Werbart, 2013). Finally, clinicians were asked to evaluate their patients' psychiatric pathology at the end of the last session, using the CPRS.

\section{Statistical analysis}

Statistical analyses were conducted using SPSS 20 for Windows (IBM, Armonk, NY). Bivariate correlations (Pearson's $r$, two-tailed) were performed with the ACSE, TRQ, and WAI-T scores to explore the associations between specific countertransference patterns and the therapeutic alliance (evaluated at the sixth therapy session), as well as therapists' subjective experiences of their patients at the first clinical assessment. A repeated measures ANOVA was carried out to detect statistically significant differences between pre- and post-treatment conditions on patients' symptom severity. Finally, bivariate correlations were performed to examine the associations between the relational variables evaluated early in the treatment (using the ACSE, TRQ, and WAI-T) and the index of patients' symptom changes evaluated at the end of STPP (6 months later). Consistent with Äsberg and Schalling's (1979) method, the index of change in the global severity of patients' illness was estimated using the mathematical difference between the CPRS total scores at the beginning and end of psychotherapy, respectively.

\section{Results}

\section{Characteristics of relational variables}

Table 2 provides the descriptive statistics of the relational variables examined in this study. The mean $(M)$ and $S D$ scores of the ACSE's scales were similar to those found in a previous study on patients suffering from depression or anxiety disorders (Pallagrosi et al., 2014). These patients tend to elicit less-intense and less-negative emotional experiences in clinicians than those with other clinical syndromes (e.g., schizophrenia) did. Notably, high scores on the engagement scale $(M=19.53 ; S D=5.80)$ obtained in this research indicate that the first interactions with patients were less distressing - possibly due to their reassuring help-seeking attitudes, which favor the development of supportive and helpful relationships with therapists. The $M$ and $S D$ scores of the TRQ's scales were mostly consistent with those obtained by the ACSE. Notably, the strongest patterns of the therapists' reactions were: i) the positive/satisfying and parental/protective countertransference $(M=2.48$ and $2.14, S D=0.80$ and 0.79 , respectively), as could be expected on the basis of the collaborative and caregiving/caretaking nature of the thera- peutic relationship; and ii) the helpless/inadequate countertransference $(M=2.14, S D=0.95)$, taking into account that, in this study, a subgroup of patients had comorbid personality disorders, and overall, these patients tend to evoke this kind of countertransference reaction (e.g., Tanzilli, Lingiardi, \& Hilsenroth, 2018). Finally, the WAIT's scores confirmed a satisfactory alliance between patients and therapists from the start of treatment, which is relevant to working collaboratively and achieving greater connection in therapy.

\section{Relationships between clinicians' early subjective experiences of the patients, countertransference patterns, and the therapeutic alliance}

The first and second aims of the study were to examine the relationships between clinicians' subjective experiences of their patients (assessed at the beginning of treatment) and both countertransference patterns and the therapeutic alliance (evaluated at the sixth STPP session). Table 3 provides the correlations between the ACSE and TRQ scales. The results were mostly consistent with our expectations, with some exceptions: TRQ positive/satisfying and parental/protective countertransference patterns were positively and significantly associated with ACSE engagement; the TRQ hostile/angry countertransference

Table 2. Means $(M)$ and standard deviations $(S D)$ for scores on the Assessment of Clinicians' Subjective Experience (ACSE), Therapist Response Questionnaire (TRQ) (Tanzilli et al., 2016), and Working Alliance Inventory-Therapist Version (WAI-T) Scales.

\begin{tabular}{lcc}
\hline Relational variables & $\boldsymbol{M}$ & $\boldsymbol{S D}$ \\
\hline ACSE scales & 5.84 & 5.73 \\
\hline Tension & 10.56 & 6.53 \\
\hline Difficulty in attunement & 19.53 & 5.80 \\
\hline Engagement & 5.28 & 3.81 \\
\hline Disconfirmation & 5.63 & 3.85 \\
\hline Impotence & & \\
\hline TRQ scales & 1.45 & .60 \\
\hline Criticized/devalued & 2.14 & .95 \\
\hline Helpless/inadequate & 2.48 & .80 \\
\hline Positive/satisfying & 2.14 & .79 \\
\hline Parental/protective & 1.63 & .54 \\
\hline Overwhelmed/disorganized & 1.26 & .28 \\
\hline Special/overinvolved & 1.15 & .36 \\
\hline Sexualized & 1.82 & 1.00 \\
\hline Disengaged & 1.53 & .67 \\
\hline Hostile/angry & 4.86 & .86 \\
\hline WAI-T total score & & \\
\hline
\end{tabular}


pattern was positively associated with ACSE disconfirmation, while the TRQ criticized/devalued countertransference pattern was positively associated with both ACSE disconfirmation and tension; and the TRQ disengaged countertransference pattern was strongly and negatively associated with ACSE engagement. On the other hand, there were some differences: the TRQ helpless/inadequate countertransference pattern did not correlate with ACSE impotence, but was positively associated with ACSE difficulty in attunement and disconfirmation. Moreover, no correlations were found between the TRQ special/overinvolved and sexualized countertransference patterns and any ACSE dimension.

Table 4 outlines the significant and coherent associations found among the ACSE, TRQ, and WAI-T scales, which confirm our hypothesis. The results show that the therapist-rated alliance was positively associated with ACSE engagement and more negatively associated with ACSE difficulty in attunement, disconfirmation, and tension. Moreover, the therapeutic alliance positively correlated with the TRQ positive/satisfying countertransference pattern and more negatively correlated with TRQ helpless/inadequate, disengaged, hostile/angry, overwhelmed/disorganized, and criticized/devalued countertransference patterns.

Outcome of short-term psychodynamic psychotherapy: relations between the index of patients' symptom changes, clinicians' early subjective experiences, countertransference patterns, and the therapeutic alliance

The third aim of the study was to investigate STPP outcomes. A repeated measures ANOVA was conducted to compare pre- and post-treatment conditions on patients' symptom severity. The results showed a statistically significant difference between CPRS total scores at the beginning and end of psychotherapy, $F(1,31)=8.39, \mathrm{P}=.007$, $\eta^{2}=.21$, Cohen's $d=-.51$. Means and standard deviations were as follows: $M_{\mathrm{CPRS} \text { beginning of treatment }}=24.31$ and $S D_{\mathrm{CPRS}}$ beginning of treatment $=10.95 ; M_{\mathrm{CPRS} \text { end of treatment }}=18.34$ and $S D_{\mathrm{CPRS}}$ end of treatment $=12.48$.

Moreover, Table 5 shows the correlations between therapists' subjective experiences at the first clinical assessment, countertransference patterns, and the therapeutic alliance assessed early in treatment, with the index of change in the global severity of patients' illnesses, as evaluated at the end of STPP. In line with the study's hypothesis, the results demonstrated that the index of patients' symptom improvement was positively associated with the WAI-T total score and negatively associated with ACSE difficulty in attunement and TRQ hostile/angry, helpless/inadequate, and disengaged countertransference patterns. However, contrary to our expectations, there were no correlations between the index of symptom change and ACSE engagement and/or the TRQ positive/satisfying countertransference pattern.

\section{Discussion and Conclusions}

This report presents the preliminary findings of an empirical investigation that sought to examine the associations between specific elements of the therapeutic relationship and STPP outcome. Notably, this study focused on countertransference patterns and the quality of the therapeutic alliance evaluated early in treatment, as well as therapists' subjective experiences in their first clinical interaction with patients, in relation to their symptom changes at the end of STPP. Overall, consistent with the clinical and empirical literature (e.g., Flückiger et al., 2018; Fonagy, 2015; Gelso, 2014; Hayes, Nelson, \& Fauth, 2015; Hayes et al., 2018; Levy et al., 2012; Shedler, 2010), the findings seem to confirm the meaningful connection between relational factors and patients' symptom improvements in STPP, supporting the position that clinicians should use their subjective re-

Table 3. Bivariate correlations between ACSE and TRQ (Tanzilli et al., 2016) Scales $(N=32)$.

\begin{tabular}{|c|c|c|c|c|c|}
\hline \multirow[b]{2}{*}{ TRQ scales } & \multicolumn{5}{|c|}{ ACSE scales } \\
\hline & Tension & Difficulty in attunement & Engagement & Disconfirmation & Impotence \\
\hline Criticized/devalued & $.60 * * *$ & .34 & -.15 & $.51 * *$ & $.53 * *$ \\
\hline Helpless/inadequate & $.41 *$ & $.58 * * *$ & $-.58 * * *$ & $.57 * * *$ & .34 \\
\hline Positive/satisfying & .01 & $-.36^{*}$ & $.64 * * *$ & $-.42 *$ & -.05 \\
\hline Parental/protective & .26 & .04 & $.61 * * *$ & .05 & .34 \\
\hline Overwhelmed/disorganized & $.55 * * *$ & .23 & -.07 & $.43 *$ & $.43 *$ \\
\hline Special/overinvolved & .17 & -.13 & .29 & -.06 & .03 \\
\hline Sexualized & .31 & .18 & .31 & .04 & .28 \\
\hline Disengaged & .12 & $.50 * *$ & $-.62 * * *$ & $.40^{*}$ & .17 \\
\hline Hostile/angry & .29 & $.38 *$ & $-.43 *$ & $.61 * * *$ & $.35^{*}$ \\
\hline
\end{tabular}

$* \mathrm{P} \leq .05 . ; * \mathrm{P} \leq .01 . ; * * \mathrm{P} \leq .001$. The table lists Pearson's $r$ values, two-tailed. 
actions within the clinical relationship to inform their therapeutic interventions and provide more effective treatment (e.g., Campbell et al., 2013; Norcross \& Lambert, 2018; Wampold, 2015).

The first aim of the study was to explore the relationships between the TRQ and ACSE scales (Pallagrosi et al., 2014; Tanzilli et al., 2016). With few exceptions, the results support our hypothesis that the two constructs are correlated in a conceptually meaningful way. Importantly, the articulated picture of correlations provided in Table 3 shows that TRQ positive/satisfying countertransference was mostly associated with ACSE engagement; this highlights that therapists' experiences of a positive working alliance, trust, and emotional connection with patients may be connected to higher levels of clinician-patient involvement at the beginning of therapy. Likewise, the strong and expected association of both TRQ criticized/devaluated and hostile/angry countertransference patterns with ACSE disconfirmation suggests that therapists' emotional reactions of rage and irritation, and their sense of being criticized, unappreciated, or devalued by patients, may be linked to early difficulty in establishing a reciprocal and genuine therapeutic relationship with patients. Also notable is the relationship between the TRQ disengaged countertransference pattern and a mixture of clinicians' subjective experiences marked by lower ACSE engagement and higher ACSE difficulty in attunement. This result suggests that therapists who perceive a lack of intimacy with their pa-

Table 4. Bivariate correlations among ACSE, TRQ, and WAI-T scales $(N=32)$.

\begin{tabular}{ll}
\hline $\begin{array}{l}\text { Therapists' subjective experience and } \\
\text { their emotional responses }\end{array}$ & WAI-T total score \\
\hline ACSE scales & $-.42^{*}$ \\
\hline Tension & $-.60 * * *$ \\
\hline Difficulty in attunement & $.77 * * *$ \\
\hline Engagement & $-.58 * * *$ \\
\hline Disconfirmation & -.27 \\
\hline Impotence & $-.39 *$ \\
\hline TRQ scales & $-.81 * * *$ \\
\hline Criticized/devalued & $.72 * * *$ \\
\hline Helpless/inadequate & .30 \\
\hline Positive/satisfying & $-.43 *$ \\
\hline Parental/Protective & .32 \\
\hline Overwhelmed/disorganized & .06 \\
\hline Special/overinvolved & $-.73^{* * *}$ \\
\hline Sexualized & \\
\hline Disengaged & \\
\hline Hostile/angry & \\
\hline
\end{tabular}

${ }^{*} \mathrm{P} \leq .05 . ; * * \mathrm{P} \leq .01 . ; * * * \mathrm{P} \leq .001$. The table lists Pearson's $r$ values, two-tailed. tients may feel less involved, aloof, and detached in their early clinical interactions. On the other hand, contrary to our expectations, no relationship was found between the TRQ helpless/inadequate countertransference pattern and ACSE impotence, suggesting that there is a weak connection between these two dimensions. Addressing the correlations presented in Table 3, it seems that therapists' feelings of impotence, hopelessness, and a strong sense of inefficacy in treatment were mostly associated with strong and heterogeneous experiences of difficulty in establishing involvement, emotional closeness, and empathy toward patients at the first clinical evaluation.

The second aim of the study was to investigate whether distinct TRQ countertransference patterns and ACSE dimensions were significantly associated with the quality of the therapeutic alliance. Overall, taking into account the correlations (and their magnitude) depicted in Table 4, the study found that higher global levels of collaboration and commitment between clinicians and patients correlated with a higher degree of engagement in the first interaction and higher levels of positive countertransference throughout the course of treatment. Moreover, consistent with previous research (Hayes et al., 2011), weaker alliance was mainly associated with therapists' more intense feelings of incompetence, failure to be helpful, or frustration, as well as emotional disattunement, withdrawal, strong anger, and distress. The present study cannot provide any casual interpretation of these correla-

Table 5. Bivariate Correlations Among the ACSE, TRQ, WAITscales evaluated early in treatment and the index of patients' symptom change as treatment outcome variable $(N=32)$.

\begin{tabular}{lc}
\hline $\begin{array}{l}\text { Therapists' subjective experience, their } \\
\text { emotional responses and therapeutic alliance }\end{array}$ & $\begin{array}{c}\text { Index of patients' } \\
\text { symptom change }\end{array}$ \\
\hline ACSE scales & -.13 \\
\hline Tension & $-.47^{* *}$ \\
\hline Difficulty in attunement & .24 \\
\hline Engagement & -.26 \\
\hline Disconfirmation & -.20 \\
\hline Impotence & -.21 \\
\hline TRQ scales & $-.40^{*}$ \\
\hline Criticized/devalued & .16 \\
\hline Helpless/inadequate & -.21 \\
\hline Positive/satisfying & -.30 \\
\hline Parental/Protective & .10 \\
\hline Overwhelmed/disorganized & .05 \\
\hline Special/overinvolved & $-.36^{*}$ \\
\hline Sexualized & $-.43^{*}$ \\
\hline Disengaged & $.35^{*}$ \\
\hline Hostile/angry & \\
\hline WAI-T total score & \\
\hline$*$ P $\leq .05 . ; *$ P $\leq .01$. The table lists Pearson's $r$ values, two-tailed. & \\
\hline
\end{tabular}


tional findings between countertransference patterns and the therapeutic alliance. However, it would be plausible to propose a reciprocal influence model in which the therapeutic alliance and therapists' emotional reactions to patients affect each other throughout treatment. Our results support this theory, as they suggest that clinicians' negative emotional reactions might provoke several challenges for managing the clinical relationship, and thus interfere with the construction and maintenance of a sufficiently strong alliance; likewise, a weak alliance (due, for example, to the therapists' difficulty in recognizing and repairing alliance ruptures; see Safran \& Muran, 2000) might lead therapists to doubt their efficacy in working with patients and to experience a strong sense of detachment and irritation in therapy (Gelso \& Hayes, 2007).

Finally, the third aim of this study was to examine the STPP outcome. Consistent with the empirical literature (e.g., Abbass et al., 2014; Driessen et al., 2015; Keefe et al., 2014), the results showed a significant symptom remission in patients at the end of treatments. Moreover, the study sought to investigate whether countertransference patterns and the quality of the therapeutic alliance evaluated early in treatment, as well as therapists' subjective experiences during their first clinical interaction with a patient, were coherently and meaningfully associated with patients' symptom changes at the end of STPP. Significant associations were found between elements of the therapeutic relationship and patients' improvement in psychiatric symptoms (Table 5). More specifically, better STPP outcomes were negatively correlated with greater difficulty in attunement, as perceived at the beginning of clinical assessment, and therapists' stronger responses of helplessness, impotence, rage, frustration, and disengagement during therapy; and positively associated with a good therapeutic alliance (Dahl et al., 2012; Flückiger et al., 2018; Gelso, 2014; Norcross \& Lambert, 2018). Contrary to our expectations, patients' improvement in psychiatric symptoms did not correlate with therapists' positive subjective experiences in their first interaction with a patient and/or countertransference patterns during the course of therapy. Consistent with the results of previous research (e.g., Hayes et al., 2015), the findings of the present study suggest that symptom reduction in STPP differs according to the degree of the therapeutic alliance and the ability of the therapist to manage the affective quality and intensity of any negative reactions experienced from first session and onwards. These findings highlight that clinicians should be able to recognize early problems in developing an empathic connection with the patient from the first stages of therapy, as well as to monitor and work through their countertransference patterns during the course of therapy; moreover, they should be sensitive to fluctuations in the alliance and apply, where necessary, interventions to address any relational difficulties that could have detrimental effects on the therapeutic work (Hilsenroth et al., 2012; Norcross \& Lambert, 2018).
Some limitations of this research deserve mention. First, it was a preliminary study and the sample of clinician-patient dyads was small; this possibly affected the statistical power of the results. Future research should extend the sample and examine in more depth the complex processes underlying the associations between relational therapeutic factors and STPP outcome. Notably, these connections should take into account the effect of other relevant variables that could serve as moderators or mediators, such as patients' personality characteristics or pretreatment symptoms (e.g., Constantino \& Smith-Hansen, 2008; Diener \& Monroe, 2011; Maffei et al, 1995; for a deeper discussion, see De Ruibeis, Brotman, \& Gibbons, 2005). For example, evidence has shown that patients who are reported by therapists to have personality problems have a much larger effect on the alliance and countertransference patterns than do other patients (e.g., Colli et al., 2014; Dahl et al., 2012, 2014; Lingiardi, Filippucci, \& Baiocco, 2005; Røssberg, Karterud, Pedersen, \& Friis, 2007; Smith, Levy, Hilsenroth, Fiori, \& Bornstein, 2016); thus, it would be informative to replicate the present analyses while controlling for the presence of personality pathology. Moreover, it would be relevant to examine the impact of prior symptom reduction on the alliance- and countertransference-outcome relationships. Some research has indicated that the alliance is not just a byproduct of prior symptomatic improvement, though symptom improvement is likely to enhance the alliance (Falkenström, Granström, \& Holmqvist, 2013). Future research should explore this issue, while including therapists' subjective responses in a more articulated model. Finally, although the majority of clinicians-participants provided data on a single patient, further investigations should include different clinicians who furnish data on relational variables with different patients, in order to avoid potential interdependencies among ratings.

In conclusion, this was the first study to have attempted to examine the effectiveness of STPP focusing on specific relational elements assessed using the TRQ and ACSE. The results confirm the precious value of the clinical relationship, which represents a useful source of information for therapists when planning therapeutic interventions (Lingiardi \& McWilliams, 2015). To avoid engaging in countertherapeutic interpersonal processes, clinicians must recognize and understand their emotional responses and subjective experiences toward their patients. Notably, training and supervision should attend to therapists' internal thought processes and emotional reactions.

\section{References}

Abbass, A. A., Kisely, S. R., Town, J. M., Leichsenring, F., Driessen, E., De Maat, S., \& ... Crowe, E. (2014). Shortterm psychodynamic psychotherapies for common mental disorders. The Cochrane Database of Systematic Reviews, (7), CD004687. doi:10.1002/14651858.CD004687.pub4 APA - American Psychiatric Association. (2000). Diagnostic and 
statistical manual of mental disorders (4th ed., text rev.). Washington, DC: Author.

Äsberg, M., Perris, C., Schalling, D., \& Sedvall, G. (1978). CPRS: Development and applications of a psychiatric rating scale. Acta Psychiatrica Scandinavica, Suppl 271, 5-27. doi:10.1111/j.1600-0447.1978.tb02357.x

Äsberg, M., \& Schalling, D. (1979). Construction of a new psychiatric rating instrument, the Comprehensive Psychopathological Rating Scale (CPRS). Progress in NeuroPsychopharmacology, 3(4), 405-412. doi:10.1016/0364-7722 (79)90055-9

Betan, E., Heim, A. K., Zittel Conklin, C., \& Westen, D. (2005). Countertransference phenomena and personality pathology in clinical practice: An empirical investigation. The American Journal of Psychiatry, 162, 890-898. doi:10.1176/ appi.ajp.162.5.890

Blagys, M. D., \& Hilsenroth, M. J. (2000). Distinctive feature of short-term psychodynamic-interpersonal psychotherapy: A review of the comparative psychotherapy process literature. Clinical Psychology: Science and Practice, 7(2), 167 188. doi:10.1093/clipsy/7.2.167

Bordin, E. S. (1979). The generalizability of the psychoanalytic concept of the working alliance. Psychotherapy: Theory, Research \& Practice, 16(3), 252-260. doi:10.1037/h0085885

Campbell, L. F., Norcross, J. C., Vasquez, M. T., \& Kaslow, N. J. (2013). Recognition of psychotherapy effectiveness: the APA resolution. Psychotherapy, 50(1), 98-101. doi:10.1037/ a0031817

Castonguay, L. G., \& Beutler, L. D. (2006). Principles of therapeutic change that work. Oxford, UK: Oxford University Press.

Colli, A., Tanzilli, A., Dimaggio, G., \& Lingiardi, V. (2014). Patient personality and therapist response: An empirical investigation. The American Journal of Psychiatry, 171, 102-108. doi.10.1176/appi.ajp.2013.13020224

Constantino, M., \& Smith-Hansen, L. (2008). Patient interpersonal factors and the therapeutic alliance in two treatments for bulimia nervosa. Psychotherapy Research, 18(6), 683698. doi:10.1080/10503300802183702

Crits-Christoph, P., \& Connolly, M. B. (1999). Alliance and technique in. short-term dynamic therapy. Clinical Psychology Review, 19, 687-704. doi:10.1016/S0272-7358(98) 00079-8

Dahl, H. J., Røssberg, J. I., Bøgwald, K. P., Gabbard, G. O., \& Høglend, P. A. (2012). Countertransference feelings in one year of individual therapy: An evaluation of the factor structure in the Feeling Word Checklist-58. Psychotherapy Research, 22(1), 12-25. doi:10.1080/10503307.2011.622312

Dahl, H. J., Røssberg, J. I., Crits-Christoph, P., Gabbard, G. O., Hersoug, A. G., Perry, J. C., \& ... Høglend, P. A. (2014). Long-term effects of analysis of the patient-therapist relationship in the context of patients' personality pathology and therapists' parental feelings. Journal of Consulting and Clinical Psychology, 82(3), 460-471. doi:10.1037/a0036410

DeRubeis, R. J., Brotman, M. A., \& Gibbons, C. J. (2005). A conceptual and methodological analysis of the nonspecifics argument. Clinical Psychology: Science and Practice, 12, 174-183. doi:10.1093/clipsy.bpi022

Diener, M. J., \& Monroe, J. M. (2011). The relationship between adult attachment style and therapeutic alliance in individual psychotherapy: a meta-analytic review. Psychotherapy, 48(3), 237-248. doi:10.1037/a0022425

Driessen, E., Hegelmaier, L. M., Abbass, A. A., Barber, J. P., Dekker, J. M., Van, H. L., \& ... Cuijpers, P. (2015). The ef- ficacy of short-term psychodynamic psychotherapy for depression: A meta-analysis update. Clinical Psychology Review, 42, 1-15. doi:10.1016/j.cpr.2015.07.004

Falkenström, F., Granström, F., Holmqvist, R. (2013). Therapeutic alliance predicts symptomatic improvement session by session. Journal of Counseling Psychology, 60(3), 317 328. doi:10.1037/a0032258

Flückiger, C., Del Re, A. C., Wampold, B. E., \& Horvath, A. O. (2018). The alliance in adult psychotherapy: A meta-analytic synthesis. Psychotherapy, 55(4), 316-340. doi:10.1037/ pst0000172

Fonagy, P. (2015). The effectiveness of psychodynamic psychotherapies: An update. World Psychiatry, 14(2), 137-150. doi:10.1002/wps.20235

Gabbard, G. O. (2009). Textbook of psychotherapeutic treatments. Arlington, VA: American Psychiatric Association Publishing.

Gaston, L., Thompson, L., Gallagher, D., Cournoyer, L. G., \& Gagnon, R. (1998). Alliance, technique, and their interactions in predicting outcome of behavioral, cognitive, and brief dynamic therapy. Psychotherapy Research, 8(2), 190 209. doi: $10.1080 / 10503309812331332307$

Gelso, C. J. (2004). Countertransference and its management in brief dynamic therapy. In D. P. Charman (Ed.), Core processes in brief psychodynamic psychotherapy: Advancing effective practice (pp. 231-250). Mahwah, NJ, US: Lawrence Erlbaum Associates Publishers.

Gelso, C. (2014). A tripartite model of the therapeutic relationship: Theory, research, and practice. Psychotherapy Research, 24, 117-131. doi:10.1080/10503307.2013.845920

Gelso, C. J., \& Hayes, J. A. (2007). Countertransference and the therapist's inner experience: Perils and possibilities. Mahwah, NJ: Erlbaum.

Hayes, J. A., Gelso, C. J., Goldberg, S., \& Kivlighan, D. M. (2018). Countertransference management and effective psychotherapy: Meta-analytic findings. Psychotherapy, 55(4), 496-507. doi:10.1037/pst0000189

Hayes, J. A., Gelso, C. J., \& Hummel, A. M. (2011). Managing countertransference. Psychotherapy, 48, 88-97. doi:10.1037/ a 0022182

Hayes, J. A., Nelson, D. L., \& Fauth, J. (2015). Countertransference in successful and unsuccessful cases of psychotherapy. Psychotherapy, 52,127-133. doi:10.1037/a0038827

Hersoug, A. G. (2004). Assessment of therapists' and patients' personality: Relationship to therapeutic technique and outcome in brief dynamic psychotherapy. Journal of Personality Assessment, 83(3), 191-20. doi:10.1207/s15327752jpa8303_03

Hilsenroth, M. J., Cromer, T., \& Ackerman, S. (2012). How to make practical use of therapeutic alliance research in your clinical work. In R. A. Levy, J. S. Ablon, \& H. Kaechele (Eds.), Psychodynamic psychotherapy research: Evidencebased practice and practice-based evidence (pp. 361-380). New York, NY: Springer Press.

Horvath, A.O. (1981). An exploratory study of the concept of therapeutic alliance and its measurement. Unpublished doctoral dissertation. University of British Columbia, Vancouver, Canada.

Horvath, A. O., \& Bedi, R. (2002). The alliance. In J. C. Norcross (Ed.), Psychotherapy relationships that work: Therapist contributions and responsiveness to patients (pp. 37-70). New York, NY: Oxford University Press.

Horvath, A. O., Del Re, A. C., Flückiger, C., \& Symonds, D. (2011). Alliance in individual psychotherapy. Psychotherapy, 48, 9-16. doi:10.1037/ a0022186 
Horvath, A., \& Greenberg, L. (1986). The development of the Working Alliance Inventory. In L. Greenberg \& W. Pinsoff (Eds.), The psychotherapeutic process: A research handbook (pp. 529-556). New York, NY: Guilford Press.

Horvath, A. O., \& Greenberg, L. S. (1989). Development and validation of the Working Alliance Inventory. Journal of Counseling Psychology, 36, 223-233. doi:10.1037/00220167.36.2.223

Keefe, J. R., McCarthy, K. S., Dinger, U., Zilcha-Mano, S., \& Barber, J. P. (2014). A meta-analytic review of psychodynamic therapies for anxiety disorders. Clinical Psychology Review, 34(4), 309-323. doi:10.1016/j.cpr.2014.03.004

Knekt, P., Laaksonen M.A., Härkänen, T., Maljanen, T., Heinonen, E., Virtala, E., \& Lindfors, O. (2012). The Helsinki Psychotherapy Study: effectiveness, sufficiency, and suitability of short- and long-term psychotherapy. In R.A. Levy, J.S. Ablon, \& H. Kächele (Eds.). Psychodynamic psychotherapy research. Evidence-based practice and practice-based evidence (pp. 71-94). Totowa, NJ: Humana Press.

Lambert, M. J. (2013). Bergin and Garfield's handbook of psychotherapy and behavior change (6th ed.). New York, NY: Wiley.

Leichsenring, F., Luyten, P., Hilsenroth, M. J., Abbass, A., Barber, J. P., Keefe, J. R., \& ... Steinert, C. (2015). Psychodynamic therapy meets evidence-based medicine: a systematic review using updated criteria. The Lancet Psychiatry, 2(7), 648-660. doi:10.1016/S2215-0366(15)00155-8

Leichsenring, F., Rabung, S., Leibing, E. (2004). The efficacy of short-term psychodynamic psychotherapy in specific psychiatric disorders. A meta-analysis. Archives of General Psychiatry, 61(12), 1208-1216. doi:10.1001/archpsyc.61. 12.1208

Levy, R. A., Ablon, J. S., \& Kächele, H. (2012). Psychodynamic psychotherapy research: Evidence-based practice and practice-based evidence. Totowa, NJ: Humana Press.

Lingiardi, V., Filippucci, L., \& Baiocco, R. (2005). Therapeutic alliance evaluation in personality disorders psychotherapy. Psychotherapy Research, 15(1-2), 45-53. doi:10.1080/ 10503300512331327047

Lingiardi, V., \& McWilliams, N. (2015). The psychodynamic diagnostic manual-2nd edition (PDM-2). World Psychiatry, 14, 237-239. doi:10.1002/wps.20233

Lingiardi, V., Muzi, L., Tanzilli, A., \& Carone, N. (2018). Do therapists' subjective variables impact on psychodynamic psychotherapy outcomes? A systematic literature review. Clinical Psychology \& Psychotherapy, 25(1), 85-101. doi:10.1002/cpp.2131

Lingiardi, V., Tanzilli, A., \& Colli, A. (2015). Does the severity of psychopathological symptoms mediate the relationship between patient personality and therapist response? Psychotherapy, 52, 228-237. doi:10.1037/a0037919

Maffei, C., Fossati, A., Lingiardi, V., Madeddu, F., Borellini, C., \& Petrachi, M. (1995). Personality maladjustment, defenses, and psychopathological symptoms in nonclinical subjects. Journal of Personality Disorders, 9(4), 330-345. doi:10.1521/pedi.1995.9.4.330

Martin, D. J., Garske, J. P., \& Davis, M. K. (2000). Relation of the therapeutic alliance with outcome and other variables: A meta-analytic review. Journal of Consulting and Clinical Psychology, 68, 438-450. doi:10.1037/0022-006X.68.3.438

McWilliams, N. (2004). Psychoanalytic psychotherapy: A practitioner's guide. New York, NY: Guilford Press.

Norcross, J. C., \& Lambert, M. J. (2018). Psychotherapy rela- tionships that work III. Psychotherapy, 55(4), 303-315. doi:10.1037/pst0000193

Pallagrosi, M., Fonzi, L., Picardi, A., \& Biondi, M. (2014). Assessing clinician's subjective experience during interaction with patients. Psychopathology, 47(2), 111-118. doi:10.1159/000351589

Pallagrosi, M., Fonzi, L., Picardi, A., \& Biondi, M. (2016). Association between clinician's subjective experience during patient evaluation and psychiatric diagnosis. Psychopathology, 49(2), 83-94. doi:10.1159/000444506

Picardi, A., Pallagrosi, M., Fonzi, L., \& Biondi, M. (2017). Psychopathological dimensions and the clinician's subjective experience. Psychiatry Research, 258, 407-414. doi:10.1016/j.psychres.2017.08.079

Roos, J., \& Werbart, A. (2013). Therapist and relationship factors influencing dropout from individual psychotherapy: A literature review. Psychotherapy Research, 23(4), 394-418. doi:10.1080/10503307.2013.775528

Røssberg, J. I., Karterud, S., Pedersen, G., \& Friis, S. (2007). An empirical study of countertransference reactions toward patients with personality disorders. Comprehensive Psychiatry, 48, 225-230. doi:10.1016/j.comppsych.2007.02.002

Safran, J. D., \& Muran, J. C. (2000). Negotiating the therapeutic alliance: A relational treatment guide. New York, NY: Guilford Press.

Shedler, J. (2010). The efficacy of psychodynamic psychotherapy. American Psychologist, 65, 98-109. doi:10.1037/ a0018378

Smith, S. W., Levy, S. R., Hilsenroth, M. J., Fiori, K., \& Bornstein, R. F. (2016). Relationship between patient swap-200 personality characteristics and therapist-rated therapeutic alliance early in treatment. Journal of Nervous \& Mental Disease 204(6), 437-444. doi:10.1097/NMD.0000000000000526.

Streiner, D. L. (2003). Being inconsistent about consistency: When coefficient alpha does and doesn't matter. Journal of Personality Assessment, 80, 217-222. doi:10.1207/ S15327752JPA8003_01

Tanzilli, A., Colli, A., Del Corno, F., \& Lingiardi, V. (2016). Factor structure, reliability, and validity of the Therapist Response Questionnaire. Personality Disorders: Theory, Research, and Treatment, 7, 147-158. doi:10.1037/per0000146

Tanzilli, A., Colli, A., Gualco, I., \& Lingiardi, V. (2018). Patient personality and relational patterns in psychotherapy: factor structure, reliability, and validity of the psychotherapy relationship questionnaire. Journal of Personality Assessment, 100(1), 96-106. doi:10.1080/00223891.2016.1272050

Tanzilli, A., Lingiardi, V., \& Hilsenroth, M. (2018). Patient SWAP200 personality dimensions and FFM traits: Do they predict therapist responses responses?. Personality Disorders: Theory, Research, and Treatment, 9(3), 250-262. doi:10.1037/per 0000260

Tanzilli, A., Muzi, L., Ronningstam, E., \& Lingiardi, V. (2017). Countertransference when working with narcissistic personality disorder: An empirical investigation. Psychotherapy, 54, 184-194. doi:10.1037/pst0000111

Wampold, B. E. (2015). How important are the common factors in psychotherapy? An update. World Psychiatry, 14(3), 270277. doi: $10.1002 /$ wps. 20238

Wampold, B. E., \& Imel, Z. E. (2015). The great psychotherapy debate: The evidence for what makes psychotherapy work (2nd ed.). New York, NY: Routledge. 